\title{
Bacteremia among liver and kidney transplant recipients: etiologic agents and antimicrobial susceptibilities
}

Authors

Kivanc Serefhanoglu ${ }^{1}$ Funda Timurkaynak ${ }^{2}$ Hande Arslan ${ }^{3}$

Hamdi Karakayali $^{4}$

${ }^{1}$ Assistant Professor, Department of Infectious Diseases and Clinical Microbiology, Medical School, Baskent Universitesi, Turkey ${ }^{2}$ Associated Professor, Department of Infectious Diseases and Clinical Microbiology, Medical School, Baskent Universitesi, Turkey ${ }^{3}$ Professor, Department of Infectious Diseases and Clinical Microbiology, Medical School, Baskent Universitesi, Turkey ${ }^{4}$ Professor, Department of General Surgery, Medical School, Baskent Universitesi, Turkey
Submitted on: $02 / 11 / 2011$ Approved on: 02/17/2011

Correspondence to: Kivanc Serefhanoglu Baskent Universitesi Istanbul Hastanesi Kisikli C Altunizade M Oymaci S No: 7 Uskudar Istanbul, Turkey kivanc1972@gmail.com

We declare no conflict of interest.

(O2011 Elsevier Editora Ltda All rights reserved.
Dear Editor,

In this retrospective study, we compared etiologies and antibiotic susceptibility patterns among kidney and liver transplant recipients with bacteremia in two 1-year periods, 2005 and 2009. Time of bacteremia onset were computed in the two post-transplant periods, first six months (early period) and more than six months (late period) after the transplantation. Clinical characteristics including age, sex, previous antibiotic or antifungal therapy within three months, comorbidities, central venous catheterization (CVC), mechanical ventilation, cytomegalovirus (CMV) disease, hemodialysis after transplantation, intra-abdominal drainage or biliary stenting, origin of bacteremia, allograft dysfunction, mortality, microbiological isolates, total parenteral nutrition were collected for the analysis.

There were 14 bacteremic episodes among six kidney and eight liver recipients in the year 2005 , and there were 23 episodes among six kidney and 17 liver recipients in the year 2009. Characteristics of the episodes in the two study periods of 2005 and 2009 were similar. Overall, there were 15 bacteremic episodes in the early period and 22 in the late period. Trimethoprim- sulphamethoxazole (TMP-SMX) prophylaxis ( $\mathrm{n}=13 v s \mathrm{n}=4, \mathrm{p}=0.0001)$ and presence of CVC $(\mathrm{n}=8 v s \mathrm{n}=4, \mathrm{p}=0.025)$ were more frequently detected in the early post-transplantation period. However, CMV disease ( $\mathrm{n}=5$ vs $\mathrm{n}=0$ ) occurred more frequently in the late period. Other characteristics of the episodes were similar in the two post transplantation periods. All infections were caused by Gramnegative bacteremia (Escherichia coli, $\mathrm{n}=16$; Klebsiella spp., $\mathrm{n}=13$; Pseudomonas spp., $\mathrm{n}=5$; Acinetobacter baumannii, $\mathrm{n}=2$; Enterobacter aerogenes, $\mathrm{n}=1$ ). No significant changes in antibiotic resistance patterns were found among microorganisms isolated in the years 2005 and 2009. However, when comparing the two post-transplantion periods, the isolates recovered during the early period demonstrated significantly higher resistance rate to ceftazidime $(\mathrm{p}=0.003)$ and cefepime $(\mathrm{p}=0.003)$ (Table 1). Multivariate logistic regression showed that the increased resistance rate to ceftazidime and cefepime was associated with onset of bacteremia in the early period (OR, 9.12; $\mathrm{p}=0.003)$, TMPSMX prophylaxis (OR, 3.40; $\mathrm{p}=0.046)$, and intra-abdominal drainage or biliary stenting $(\mathrm{OR}, 4.61, \mathrm{p}=0.032)$.

Table 1. Antibiotic resistance patterns in Gram-negative bacteria causing bacteremia in liver and kidney transplantation recipients according to two post-transplantation periods, $n(\%) *$

\begin{tabular}{lccc}
\hline & $\mathbf{1 - 6}$ months & $>\mathbf{6}$ months & $\mathbf{p}$ \\
\hline Ciprofloxacin & $6(46)$ & $7(54)$ & $>0.05$ \\
\hline Ceftazidime & $10(71.4)$ & $4(28.6)$ & 0.003 \\
\hline Piperacillin-tazobactam & $4(44.2)$ & $5(55.8)$ & $>0.05$ \\
\hline Cefepime & $10(71.4)$ & $4(28.6)$ & 0.003 \\
\hline Amikacin & $1(100)$ & 0 & $>0.05$ \\
\hline Imipenem & $1(50)$ & $1(50)$ & $>0.05$
\end{tabular}

* Univariate analysis. 
Microorganisms responsible for infections in our study were entirely Gram-negative bacteria, in contrast to the publications of Kawecki et al., ${ }^{1}$ where the microorganisms responsible for bloodstream infections among solid organ recipients were predominantly Gram-positive bacteria. Multiple antibiotic-resistant bacteremia during the early period after transplantation observed in our study was also described by Linares et al. ${ }^{2}$ To the best of our knowledge, this is the first study reporting TMP-SMX prophylaxis and intra-abdominal drainage or biliary stenting as independent risk factors for resistance to ceftazidime and cefepime in bloodstream isolates in this setting of patients.

In conclusion, Gram-negative bacteria should be considered if bloodstream infection is suspected among solid organ transplant recipients. Multidrug-resistant pathogens may especially be of great concern among patients with early bacteremia after solid organ transplantation.

\section{REFERENCES}

1. Kawecki D, Chmura A, Pacholczyk M et al. Etiological agents of bacteremia in the early period after liver transplantation. Transplant Proc 2007; 39:2816.

2. Linares L, García-Goez JF, Cervera C et al. Early bacteremia after solid organ transplantation. Transplant Proc 2009; 41:2262, 